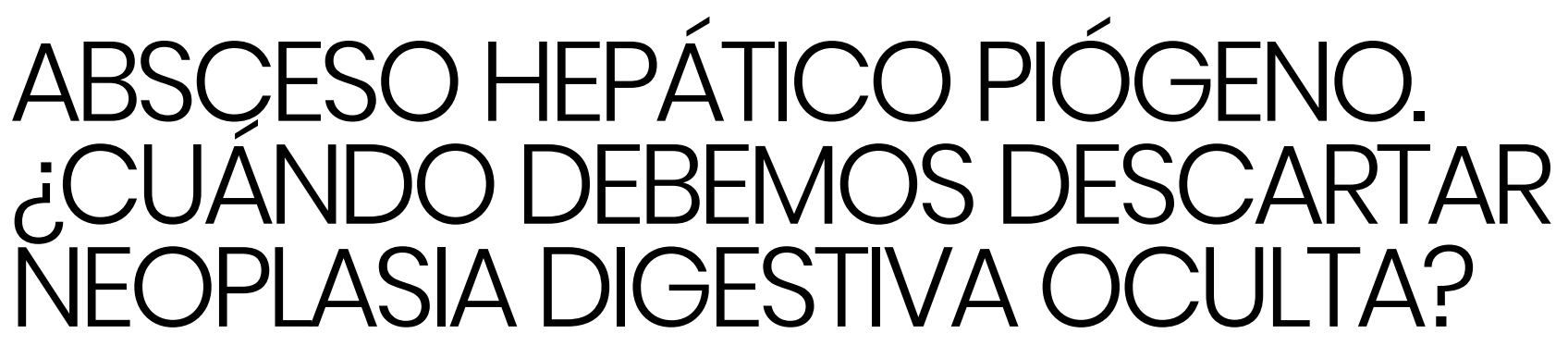

\title{
PYOGENIC LIVER ABSCESS. WHEN SHOULD WE RULE OUT HIDDEN DIGESTIVE NEOPLASIA?
}

\author{
Pardillos Tomé A', Guillén Gómez $\mathrm{M}^{2}$, Comín Orce $\mathrm{A}^{2}$, Marcilla Córdoba F \\ 'Hospital Ernest Lluch. Calatayud. Zaragoza. \\ ${ }^{2}$ Hospital Miguel Servet. Zaragoza. \\ ${ }^{3}$ Hospital de Alcañiz. Teruel.
}

Palabras clave: absceso hepático piógeno, cáncer colorrectal; Streptococcus constellatus.

Keywords: pyogenic liver abscess; colorectal cancer, Streptococcus constellatus.
Sr. Editor:

El absceso hepático piógeno (AHP) es una patología infrecuente, con una incidencia entre 1,0 a 2,3 por 100.000 habitantes en el medio occidental ${ }^{1}$ y 17,6 en población asiática ${ }^{2}$. Se han establecido factores de riesgo como la diabetes, las enfermedades biliopancreáticas y la presencia de neoplasia gastrointestinal.

Presentamos el caso de un varón de 33 años, fumador de 20 cigarrillos al día. Consulta por dolor en hipocondrio derecho y fiebre de 39 o $C$ de 7 días de evolución. No refiere cambios en el ritmo deposicional ni productos patológicos en las heces. No ha viajado a otros países. Ha presentado infecciones dentarias de repetición en los últimos meses, requiriendo antibiótico y extracción dentaria hace 1 mes. A su llegada, presenta TA 100/60 mmHg, 95 lpm, saturación de oxígeno de $99 \%$ y 39 으 de temperatura. La exploración física es 
normal. No se auscultan soplos. En la cavidad oral se observan signos de mala higiene bucal y ausencia de varias piezas dentarias, sin signos actuales de infección. Analíticamente, destaca leucocitosis 12.200 con neutrofilia (78\%), elevación de ferritina $(1185 \mathrm{ng} / \mathrm{mL}$ ) y PCR (10 mg/dl). El resto de parámetros analíticos es normal, incluyendo perfil hepático. Se realiza ecografía y TAC abdominal, mostrando lesión hipocaptante de $85 \mathrm{~mm}$ con gas en su interior, localizada en segmento III de lóbulo hepático izquierdo, compatible con absceso hepático (Figura 1). Se realiza drenaje guiado por TAC, obteniendo abundante contenido purulento, y comienza tratamiento empírico con ceftriaxona y metronidazol intravenosos. En el cultivo del aspirado crece Streptococcus constellatus, sensible a cefalosporinas. Los hemocultivos son estériles y la serología de Entamoeba histolytica es negativa. Recibe antibioterapia parenteral durante 2 semanas, completando hasta 6 con amoxicilina-clavulánico oral. Continuó seguimiento ambulatorio con resolución clínica y radiológica completa.
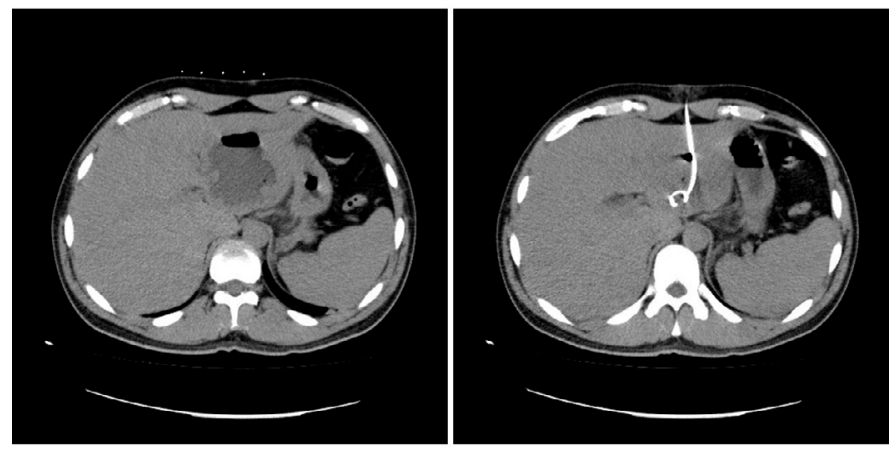

Figura 1

A. Absceso en lóbulo hepático izquierdo con nivel hidroaéreo en su interior. B. Imagen tras colocación de drenaje percutáneo.

Entre los mecanismos de producción del AHP, el más frecuente es la infección ascendente desde el árbol biliar. También puede deberse a propagación desde el sistema venoso portal (pileflebitis) a partir de un foco infeccioso abdominal (como apendicitis, diverticulitis o peritonitis), bacteriemia desde otro foco a distancia, extensión por contigüidad de un foco infeccioso abdominal o infección de una lesión metastásica hepática. El espectro microbiológico es variable dependiendo de la población a estudio y la etiología, siendo Escherichia coli el más frecuente en nuestro medio. El origen del AHP es incierto hasta en el $22 \%$ de los casos.

En nuestro caso, el microorganismo responsable fue Streptococcus constellatus, que junto a Streptococcus anginosus e intermedium conforman el grupo "milleri". S. constellatus forma parte de la flora habitual de cavidad orofaríngea, tracto gastrointestinal y vagina. De forma infrecuente se comporta como patógeno, destacando su tendencia a formar abscesos, especialmente en pacientes inmunodeprimidos o diabéticos. Han sido publicados casos de AHP, abscesos cerebrales o endocarditis por $\mathrm{S}$. constellatus secundarios a manipulación o foco infeccioso dentario ${ }^{3}$.
El AHP se ha asociado a mayor riesgo de cáncer gastrointestinal, siendo 4 veces más frecuente en estos pacientes. Se ha descrito mayor incidencia de cáncer colorrectal (CRC), seguido de cáncer hepatobiliar, pancreático y de intestino delgado ${ }^{4}$. También se han reportado casos de AHP secundario a adenomas colónicos avanzados. Esto puede deberse a diseminación bacteriana a través de la disrupción de la mucosa colónica en estas lesiones. El riesgo de CCR es mayor durante los primeros 3 meses tras el diagnóstico del AHP, manteniéndose elevado hasta 5 años después. En el $15 \%$ de los casos, el AHP puede ser la primera manifestación de una neoplasia digestiva oculta ${ }^{5}$. Hay autores que recomiendan una evaluación gastrointestinal completa en casos de AHP criptogenético. Muchos de estos estudios son de origen asiático, donde Klebsiella pneumoniae es el microorganismo más frecuentemente aislado.

¿Sería recomendable investigar la presencia de cáncer colorrectal u otros tipos de cáncer digestivo en los pacientes con AHP? Bajo nuestra opinión los pacientes con AHP deben ser evaluados minuciosamente, debiendo valorarse la investigación de neoplasia silente especialmente en los casos de AHP de origen no aclarado o sin un origen infeccioso evidente, pacientes inmunocomprometidos, diabéticos o en casos de fracaso terapéutico o recurrencia, con el fin de alcanzar un diagnóstico precoz de enfermedad neoplásica. En nuestro caso optamos por realizar seguimiento clínico estrecho, ya que atribuimos el origen del AHP a la bacteriemia producida desde el foco infeccioso dentario.

\section{Bibliografía}

1. Kaplan GG, Gregson DB, Laupland KB. Population-based study of the epidemiology of and the risk factors for pyogenic liver abscess. Clin Gastroenterol Hepatol. 2004;2(11):1032-1038. doi:10.1016/s1542-3565(04)00459-8.

2. Tsai FC, Huang YT, Chang LY, Wang JT. Pyogenic liver abscess as endemic disease, Taiwan. Emerg Infect Dis. 2008;14(10):1592-1600. doi:10.3201/ eid1410.071254.

3. Yilmaz H, Yilmaz EM, Karadag A, Esen S, Sunbul M, Leblebicioglu H. Liver abscess associated with an oral flora bacterium Streptococcus anginosus. J Microbiol Infect Dis. 2012; 2(1):33-35. doi: 10.5799/ahinjs.02.2012.01.0039.

4. Lai HC, Lin CC, Cheng KS, et al. Increased incidence of gastrointestinal cancers among patients with pyogenic liver abscess: a population-based cohort study. 